\title{
Perfil do consumidor de carnes do Alto Pantanal sul-mato-grossense
}

\author{
Profile of meat consumers of the Pantanal sul-mato-grossense
}

\author{
Júlia Dias Nascimento ${ }^{1 *}$, Dalton Mendes De Oliveira ${ }^{1}$, Talita De Oliveira Freitas Rocha ${ }^{1}$, Rosileide Vilalba Rohod ${ }^{2}$, \\ Cleiton José Piazzon ${ }^{1}$, Loraine Saldanha Escobar ${ }^{1}$ \\ ${ }^{1}$ Universidade Estadual Do Mato Grosso do Sul (UEMS), Campo Grande, MS, Brasil \\ ${ }^{2}$ Universidade Estadual de Maringá (UEM), Maringá, PR, Brasil
}

\section{Resumo}

0 objetivo deste trabalho foi avaliar o perfil dos consumidores do Alto Pantanal sul-mato-grossense, comparando o consumo e o local de aquisição das carnes de bovinos, aves, suínos, caprinos/ovinos e pescado. 0 estudo foi realizado no município de Aquidauana, localizado no Alto Pantanal sul-mato-grossense, com dados coletados entre agosto e novembro de 2015, por meio de questionário nos locais de comércio, com a participação de 501 consumidores. A carne menos consumida pelos entrevistados foi o pescado (31\%) e a mais consumida, a carne bovina (84\%). 0 principal fator citado para o consumo da carne bovina foi o sabor (60\%). Para a carne de frango, o principal fator que influencia positivamente o consumo foi o custo (37\%), sendo este fator também citado para o pescado, porém influenciando negativamente o consumo (16\%). Observou-se que $38 \%$ dos entrevistados possuem preferência pelo mesmo estabelecimento para a aquisição de carne, e que a aparência da peça é o principal atributo para a sua aquisição (34\%). Sobre a existência de selos de certificação de carne, $54 \%$ dos entrevistados declararam conhecer sua existência. Com relação aos cortes comerciais, a picanha bovina (Biceps femoris) foi o corte com a maior distância entre os valores de preferência e de consumo, sendo preferido por $12,8 \%$ dos consumidores, mas adquirido por somente 1,8\%. Em contrapartida, para os cortes de frango o preferido foi o de maior consumo. Os consumidores do Alto Pantanal sul-mato-grossense apresentam como preferência de consumo a carne bovina. A facilidade de crédito nos estabelecimentos de comércio de carne é um fator relevante para a fidelização dos consumidores nesses estabelecimentos. A praticidade, a disponibilidade, o custo e o sabor da carne são fatores que influenciam a escolha por uma determinada espécie animal. Os consumidores possuem conhecimento sobre a existência de selos de certificação de carne, porém não os exigem para a compra. O consumidor de carne bovina escolhe o corte em função do custo prioritariamente à preferência, comportamento não observado para as outras espécies animais.

Palavras-chave: Certificação. Comportamento do consumidor. Marketing. Produtos cárneos. 


\section{Abstract}

The aim of this study was to assess the profile of the consumers from the Pantanal highlands in the state of Mato Grosso do Sul, comparing the consumption and the place of purchase of beef, chicken, pork, goat/lamb and fish. The study was carried out in the city of Aquidauana, located in the highlands of Pantanal in the state of Mato Grosso do Sul, Brazil, having the data been collected from 501 consumers, in commercial places, by using a questionnaire, between August and November 2015. The meat which was less consumed by the interviewees was fish (31\%) and the most consumed one was beef (84\%). The main factor mentioned for the consumption of beef was its flavour (60\%). Regarding chicken, the main factor which positively influences its consumption is its cost (37\%), being the same factor mentioned for fish, butnegatively influencing its consumption (16\%). It was observed that 38\% of the respondents prefer to always purchase their meat in the same establishment, and that the appearance of the meat piece is the main reason for the purchase (34\%). Regarding the existence of meat certificate stamps, 54\% of the respondents stated that they were aware they existed. In relation to commercial cuts, rump cap (Biceps femoris) was the cut with the largest distance between preference and consumption values, being preferred by $12.8 \%$ of the consumers, but purchased by only $1.8 \%$. On the other hand, regarding chicken, the preferred cut was also the most consumed one. According to the interview, consumers from the Pantanal highlands in the state of Mato Grosso do Sul prefer beef for their consumption. According to the interview, the easy access to buying on credit in commercial establishments where meat is sold is a relevant factor for the consumer's loyalty to these establishments. The convenience, the availability, the cost and the flavour of the meat are factors which influence the choice of a particular animal species. Consumers are aware of the existence of meat certificate stamps; however, they do not require it when purchasing meat. Beef consumers choose meat cuts based on price, rather than preference, behaviour not observed for the other animal species.

Keywords: Certification. Consumer behaviour. Marketing. Meat products.

\section{Introdução}

A diversidade em sistemas produtivos e o amplo território nacional refletem-se na diversificação dos produtos brasileiros, permitindo ao país o atendimento a diversos mercados. Assim, é possível o aumento dos volumes e a diversidade de exportação a diferentes países que, por sua vez, exigem produtos de alta qualidade. Essa demanda é reflexo do aumento da exigência dos consumidores, que estão cada vez mais atentos às informações referentes ao processo de produção dos alimentos, modo de criação dos animais e características dos produtos, como valor nutricional, embalagem e prazo de vida de prateleira.

De acordo com Engel et al. (2000), o comportamento do consumidor pode ser definido como atividades diretamente envolvidas em obter, consumir e dispor de produtos e serviços, incluindo os processos decisórios que antecedem e sucedem estas ações. Desta forma, com o consumidor mais consciente e interessado, torna-se necessária a compreensão dos fatores que influenciam seu comportamento, possibilitando, assim, uma visão mais crítica da dinâmica de compra (Diniz et al., 2012).

Tais diferenças comportamentais passam a fazer parte das estratégias de marketing das empresas que, por sua vez, têm como finalidade buscar e atender as necessidades e os desejos dos consumidores, além de se adequarem de maneira mais eficiente do que as concorrentes. Assim sendo, o estudo de mercado torna-se uma ferramenta de suma importância para avaliar as novas tendências e as preferências dos consumidores, além de determinar quais fatores são considerados na escolha de um determinado produto (Brisola e Castro, 2005).

Uma das vantagens das informações obtidas por meio de pesquisas de mercado é que elas podem ser transmitidas à toda a cadeia produtiva, englobando produtores, atacado e varejo, a fim de que estes se adequem às novas tendências e exigências dos consumidores, independente de qual produto forneçam (Raimundo e Zen, 2010). Nesse sentindo, é possível observar alterações no comportamento dos consumidores em relação ao consumo de carne, bem como aos cortes adquiridos (Francisco et al., 2007), causadas pelas mudanças sociais como a maior participação feminina no mercado de trabalho, a redução do número de pessoas por moradia e o menor tempo disponível para o preparo dos alimentos. 
Neste contexto, o objetivo deste trabalho foi avaliar o perfil dos consumidores do Alto Pantanal sul-mato-grossense, comparando a forma de consumo e o local de aquisição das carnes de bovinos, aves, suínos, caprinos/ovinos e pescado.

\section{Materiais e métodos}

0 estudo foi realizado no município de Aquidauana, estado do Mato Grosso do Sul, a aproximadamente $130 \mathrm{~km}$ da capital, Campo Grande. Segundo o Instituto Brasileiro de Geografia e Estatística, o município de Aquidauana representa $21 \%$ da população do Pantanal do estado, com uma população estimada para o ano de 2016 de 47.323 habitantes (IBGE, 2010).

A execução da pesquisa foi dividida em duas etapas. A primeira consistiu na estruturação do questionário pelos autores, seguida da interação com os responsáveis nos locais de comércio e finalizada com o treinamento da equipe de entrevistadores, composta de sete pessoas. A segunda etapa compreendeu a aplicação do questionário e, posteriormente, a interpretação dos dados.

O cálculo amostral da população foi realizado de acordocom MartinseAspinwall(2001), utilizando-se nível de segurança de 95\% e analisando-se 501 questionários. Os questionários foram aplicados na região externa dos diferentes estabelecimentos comerciais, que compreenderam dois açougues e seis supermercados, de pequeno, médio e grande porte, independentemente do produto que comercializavam, em dias e horários distintos, de agosto a novembro de 2015.

As variáveis estudadas quanto ao perfil sócioeconômico da população foram gênero, idade, nível de formação escolar, renda e estado civil. Quanto ao consumo de carnes das diferentes espécies animais, as variáveis foram espécie de maior e menor consumo, frequência de consumo, fatores que influenciam a compra ou a rejeição, e local de aquisição.

Os atributos levados em consideração para escolha da carne foram avaliados em escala tipo Likert, em três graus de importância, onde grau 1 foi considerado item de maior importância, grau
2 de importância mediana e grau 3 de menor importância. Os resultados foram submetidos ao cálculo de frequência relativa e expressos em porcentagem.

Adicionalmente, buscou-se avaliar o perfil do local de compra, o conhecimento de certificação, bem como o modo de aquisição da carne de cada espécie animal estudada, além de comparar os cortes de maior preferência e os adquiridos para o consumo, e o modo de preparo mais conveniente.

\section{Resultados e discussão}

Com relação aos dados do perfil socioeconômico dos 501 entrevistados, observou-se que a maioria era do sexo masculino (57\%) e de faixa etária de 18 a 25 anos (17\%). A maior porcentagem dos consumidores possui ensino fundamental incompleto (28\%), renda familiar de um a três salários mínimos (81\%) e estado civil casado (55\%).

Dentre as espécies estudadas nesta pesquisa, foi possível constatar preferência pela carne bovina (84\%), seguida da carne de aves (13\%). Santos et al. (2011) pesquisaram o consumo de carne na mesma região e encontraram resultados similares quanto à preferência pela carne bovina $(90,6 \%)$. Este comportamento de escolha está diretamente ligado à cultura local, uma vez que a região possui uma forte produção de bovinos de corte (Santos et al., 2011).

Quando questionados sobre a espécie de carne menos consumida, $31 \%$ dos entrevistados alegaram ser a de peixe. As carnes suína e de caprinos/ovinos também foram classificadas na lista de menor consumo, visto que $25 \%$ dos entrevistados elegeram essas espécies como as menos consumidas.

Com relação à frequência de consumo da carne de cada espécie animal, pode-se observar que a carne bovina é consumida diariamente por $60 \%$ dos entrevistados que a tem como de preferência, enquanto que apenas $7 \%$ dos entrevistados consomem a carne de frango com a mesma frequência. Quando analisado o consumo na categoria duas vezes por semana, 32\% dos entrevistados incluem carne de aves, ao passo que há redução do consumo da carne bovina, o que representa um efeito substitutivo que pode ser correlacionado ao menor preço da carne de frango. Para as espécies menos consumidas, foi 
possível observar que essas carnes são adquiridas quinzenalmente, no caso da carne de peixe $(25 \%)$ e de suínos (20\%), e apenas em datas comemorativas no caso da carne de caprinos/ovinos (27\%).

Em outras regiões do país, o perfil de consumo em relação às diferentes espécies de carne é semelhante ao dos consumidores do Alto Pantanal sul-mato-grossense. Raimundo e Batalha (2015), estudando o mercado consumidor de carne suína no estado de São Paulo, constataram que a maior parcela dos entrevistados declarou consumir a carne oriunda dessa espécie entre duas e três vezes por mês. De maneira similar, Bortoli et al. (2009), ao avaliarem o consumidor de carne ovina na cidade de Porto Alegre, RS, constataram que a espécie é consumida em média a cada 15 dias, o que, de acordo com os autores, evidencia um consumo ocasional e impulsionado por causas que precisam ser compreendidas a fim de estabelecer estratégias para aumentar o consumo dessa espécie animal.

Divergindo dos resultados deste estudo, Almeida et al. (2014), ao avaliarem o consumo de pescado na cidade de Campo Grande, MS, identificaram que $93,3 \%$ dos entrevistados consomem carne de peixe. Quanto à frequência de consumo, porém, o maior percentual (29\%) alegou que consome eventualmente, $20 \%$ uma vez a cada quinze dias, $17 \%$ uma vez por mês, $17 \%$ uma vez por semana, $8 \%$ mais de uma vez por semana, e 3\% declararam consumir carne de peixe apenas na quaresma.

As carnes oriundas de espécies com perfil de consumo ocasional requerem alto e contínuo padrão de qualidade, novos cortes que se adequem à necessidade dos consumidores, e novas estratégias de marketing a fim de reduzir o intervalo de compra pelo consumidor, exigindo a organização da cadeia produtiva em todos os seus componentes (Bortoli et al., 2009). Um exemplo dessas estratégias foi apontado por Sório e Mariani (2008) que, em pesquisa exploratória, identificaram que o Mato Grosso do Sul é caracterizado por inúmeras regiões e cidades turísticas com diversas festas gastronômicas, como a Festa da Linguiça, na cidade de Maracaju, a Festa do Porco no Rolete, em São Gabriel d'Oeste, e as Festas do Peixe de Porto Murtinho e Coxim. Estas são iniciativas que aliaram a gastronomia ao turismo, onde trabalha-se o marketing a fim de alavancar o consumo de uma determinada espécie animal.
Dentro deste contexto, uma medida que poderia aumentar o consumo de peixes na região do Alto Pantanal sul-mato-grossense, aliando a gastronomia ao turismo, seria a realização de festivais gastronômicos com diversidade no modo de preparo do pescado, assim como a oferta de produtos com preço mais acessível, uma vez que a região é banhada por rios e cercada por restaurantes com pratos à base de pescado.

Ao avaliar os aspectos positivos levados em consideração pela população no momento da compra da carne bovina, a praticidade (9\%), a grande oferta $(11 \%)$ e o sabor $(60 \%)$ foram as características citadas pelos entrevistados como determinantes na escolha dessa espécie. 0 menor custo da carne de frango em relação à carne bovina é o que impulsiona o seu consumo para $37 \%$ dos entrevistados, assim como o fato de ser considerada saudável por $10 \%$ dos consumidores. Para os consumidores que apreciam a carne de peixe, $11 \%$ a consideraram saudável e $31 \%$ a consideram saborosa.

A respeito dos pontos negativos atribuídos pelos consumidores à cada espécie animal, o preço da carne de peixes nos pontos de comercialização é o principal fator negativo, sendo apontado por $17 \%$ dos entrevistados para justificarem seu baixo consumo, bem como a baixa oferta nos pontos de comercialização do município (14\%).

Com relaçãoà carnesuína, segunda espéciemenos consumida, os fatores que acabam influenciando negativamente a sua escolha são o alto preço (6\%), a baixa oferta (7\%) e o sabor (17\%). Adicionalmente, $8 \%$ dos entrevistados acreditam que a carne dessa espécie não é saudável pela crença de que a gordura presente pode aumentar os níveis de colesterol sanguíneo, prejudicial à saúde. Por outro lado, 10\% alegam falta de confiança na sanidade da carne, por acreditarem que pode transmitir doenças.

Para a carne de frango, 5\% dos entrevistados alegaram não consumi-la devido ao sabor e 3\% alegaram não confiar na sanidade dessa espécie animal. Esse resultado pode estar relacionado ao mito de que as aves recebem hormônios durante a criação, a fim de acelerar seu crescimento e ganhar peso mais rápido. Este fato também foi constatado por Francisco et al. (2007), ao observarem que 89\% dos entrevistados acreditavam que as aves recebiam hormônios em sua alimentação. 
No que se refere à carne ovina, $27 \%$ dos entrevistados alegaram que o sabor afeta negativamente seu consumo. Sório e Mariani (2008) afirmam que a ovinocultura é uma atividade secundária à bovinocultura de corte no estado do Mato Grosso do Sul, e que em decorrência disso, a carne ovina comercializada na região é procedente de animais com idade avançada e mal terminados, sendo, por isso, pouco apreciada pelos consumidores. Este histórico da ovinocultura sul mato-grossense exposto por Sório e Mariani (2008) possivelmente ainda repercute no consumo da espécie nos dias atuais, uma vez que $36,6 \%$ dos entrevistados alegaram não gostar de carne ovina, sendo esse o principal motivo para seu baixo consumo na região. Adicionalmente, a pouca oferta (24\%) nos pontos de venda também foi apontada como motivo para o baixo consumo de carne ovina.

Com relação ao local de compra, a tendência em concentrá-la em um só lugar ficou evidente nesta pesquisa, visto que a maioria dos entrevistados adquire a carne, de todas as espécies estudadas, em supermercados. Esse comportamento para a escolha do principal local de compra pode estar relacionado ao fato de que os entrevistados realizam compras mensais em supermercados, devido à maior diversidade e disponibilidade de produtos e de ofertas. 0 mesmo ocorre na cidade de Jundiaí, SP, onde os consumidores de carne suína alegaram escolher o supermercado como o principal local para a compra devido à praticidade $\mathrm{e}$ disponibilidade do produto. E ainda, de acordo com os entrevistados, a preferência pelo supermercado se dá por acreditarem ser este um local mais limpo e higiênico (Raimundo e Zen, 2010). Esses resultados mostram a importância dos supermercados como pontos de venda de produtos cárneos, bem como o impacto que estratégias de marketing nestes locais podem causar sobre os consumidores e sobre o volume de produtos comercializados.

Com relação aos atributos levados em consideração pelos entrevistados para a escolha do local de compra, 38\% afirmaram frequentar sempre o mesmo estabelecimento pela facilidade de crédito e 32\% afirmaram escolher o local de compra pelo preço, enquanto que apenas $12 \%$ afirmaram escolhê-lo pela localização. Além disso, foi observado que a maioria dos entrevistados não leva em consideração fatores relacionados à segurança do alimento ao escolher o local de compra, pois somente $6 \%$ indicaram a qualidade, $4 \%$ a higiene das instalações, $1 \%$ o selo de inspeção sanitária e $1 \%$ a forma de conservação dos produtos como fator de decisão para o local de compra.

Com relação ao grau de importância dos fatores que influenciam a escolha do produto pelo consumidor, $34 \%$ dos entrevistados destacam como parâmetro grau 1, de maior importância, a aparência da carne. Outro fator que se destaca é o prazo de validade do produto, sendo indicado como grau 1 por $13 \%$ dos entrevistados. Por outro lado, a forma de conservação do produto foi considerada como grau 1 por apenas 6\% dos entrevistados. Verificou-se, também, que a população letrada pouco se preocupa com o selo de inspeção sanitária da carne, sendo este fator considerado pela maioria dos entrevistados como grau 3, e como grau 1 por somente 6\% (Figura 1).

O comportamento dos consumidores em escolher os produtos pela aparência também foi relatado por outros autores. Francisco et al. (2007) identificaram que as características sensoriais foram as mais importantes para o consumidor de carne de frango da cidade de Porto Alegre, RS. Brisola e Castro (2005), ao estudarem as preferências do consumidor de carne bovina no Distrito Federal, constataram que os atributos observados no momento de compra pelos consumidores foram a conservação adequada dos produtos $(97,6 \%)$, higiene das instalações $(96,6 \%)$ e o selo de fiscalização sanitária $(80,5 \%)$. No que se refere aos atributos intrínsecos da carne, os mais citados no presente estudo foram a percepção de higiene $(88,8 \%)$, a coloração $(88,8 \%)$, a maciez $(77,5 \%)$ e a cor da gordura $(71,4 \%)$.

Com relação ao conhecimento de certificação, $54 \%$ dos entrevistados declararam ter conhecimento de sua existência, enquanto outros $45 \%$ alegaram não possuir conhecimento e 1\% não soube opinar. Dos entrevistados que alegaram conhecimento sobre a certificação, 98\% a consideram importante, enquanto apenas $2 \%$ alegaram não ser um fator importante. Ademais, $60 \%$ alegaram não fazer exigência sobre a certificação no momento da compra, sendo que apenas $40 \%$ de fato a exigem. Além disso, grande parte dos consumidores do município (65\%) alegaram estarem dispostos a pagar mais pela carne certificada. 
Quando questionados sobre o tipo de certificação de maior interesse, os entrevistados informaram a seguinte preferência em ordem decrescente: qualidade (47\%), sanidade (38\%), rastreabilidade (5\%), produção orgânica (4\%), marca (3\%) e 4\% não souberam opinar. Francisco et al. (2007) identificaram que para seus entrevistados, o selo de garantida de qualidade é de suma importância e que os consumidores estão dispostos a pagar por isso.

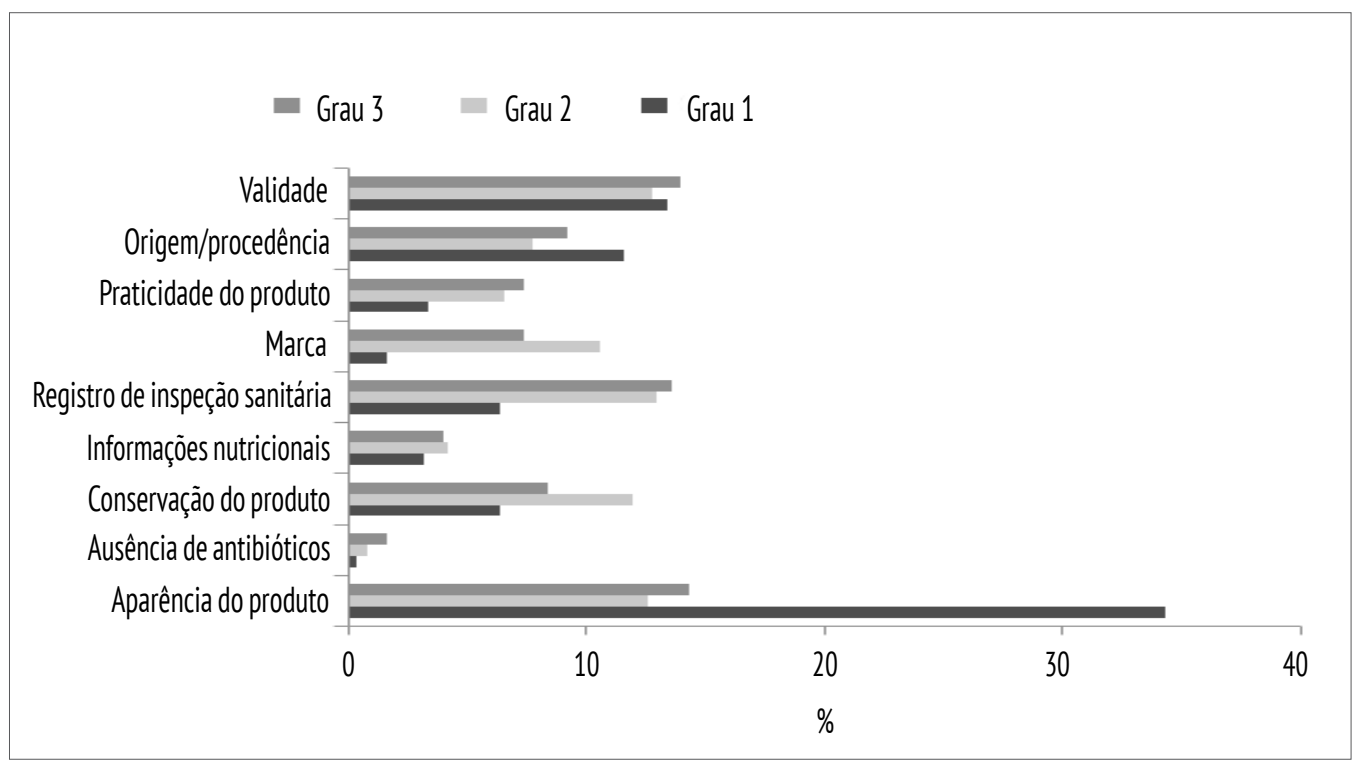

Figura 1 - Fatores levados em consideração para a escolha de carne pelos consumidores do Alto Pantanal sul-mato-grossense, avaliados em graus de importância.

A fim de avaliar a aquisição dos cortes de carne bovina, foram elencados 10 cortes, que são facilmente encontrados em qualquer açougue ou supermercado, e os entrevistados foram questionados quanto aos cortes preferidos e os realmente adquiridos para consumo. Podese observar (Figura 2) que o contrafilé, a paleta e a picanha são cortes de maior preferência. Entretanto, o coxão mole é o corte adquirido com mais frequência pelos entrevistados.

Os cortes preferidos de carne bovina, geralmente considerados cortes de primeira, nem sempre são adquiridos pelos consumidores para consumo diário, devido ao seu valor de mercado acima da média dos demais cortes. 0 poder aquisitivo da população entrevistada, que em sua maioria possui renda entre um e três salários mínimos, pode ser o principal fator limitante para a aquisição do corte cárneo preferido.

Semelhante aos resultados deste trabalho, Dias et al. (2015), ao estudarem os padrões de consumo de carne bovina na cidade de Campo Grande, MS, observaram que os cortes mais adquiridos pelos consumidores foram coxão mole $(57,11 \%)$, contra filé $(34,97 \%)$ e alcatra $(28,67 \%)$.

Diferentemente do comportamento observado para a compra dos cortes de carne bovina, na pesquisa sobre aquisição e consumo de cortes de frango (Figura 3) houve relação direta entre os cortes preferidos e os consumidos. Este comportamento se deve ao custo da carne de frango que, quando comparada à bovina, é menor, permitindo ao consumidor escolher o corte que mais lhe agrada, independentemente do valor de aquisição. Outros $57 \%$ dos entrevistados não souberam opinar sobre os cortes de frango, o que pode estar relacionado ao fato de os entrevistados não consumirem esta espécie animal ou ao fato do corte que costumam adquirir não estar elencado entre os sete cortes selecionados neste estudo. 


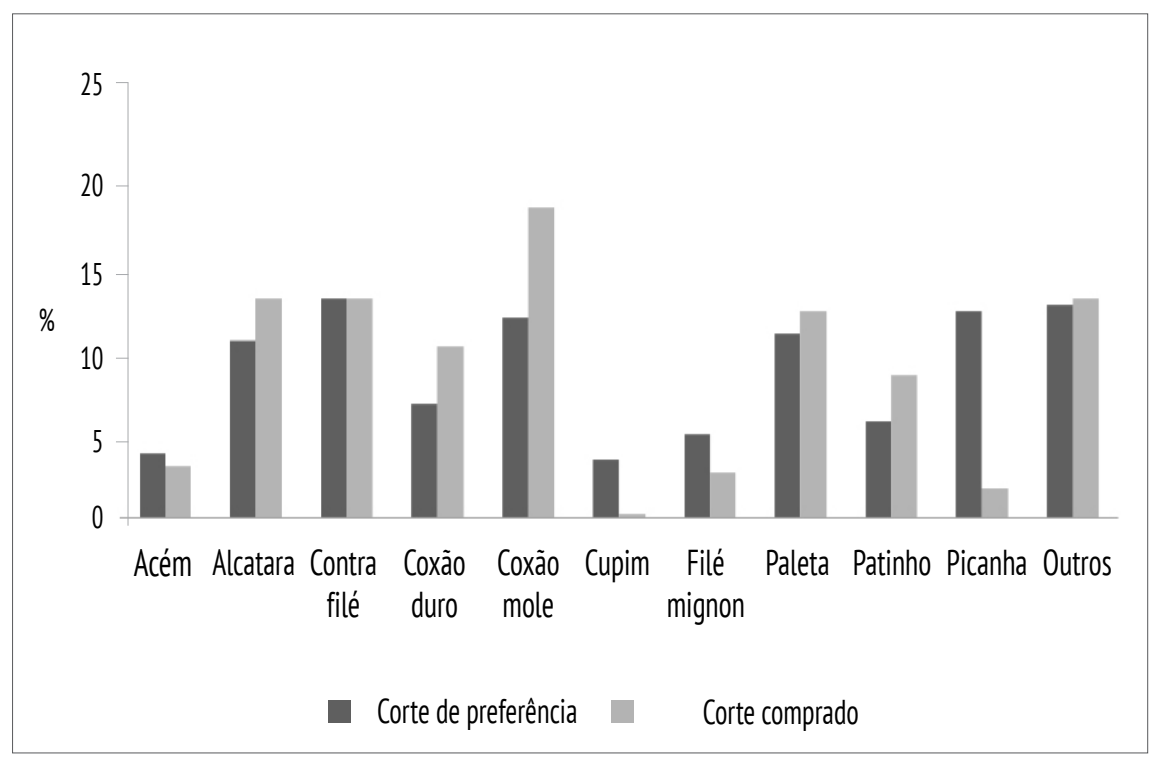

Figura 2 - Relação entre cortes de carne bovina de preferência e os realmente adquiridos pelos consumidores do Alto Pantanal sulmato-grossense.

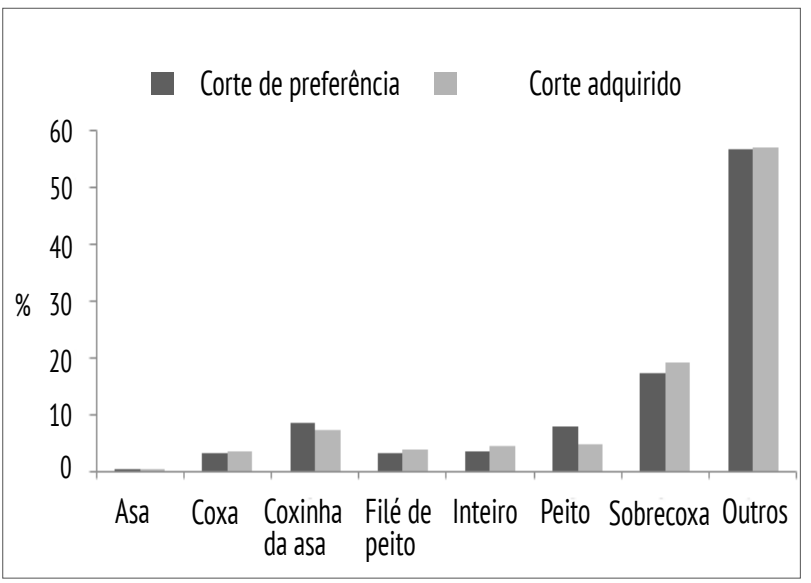

Figura 3 - Relação entre corte de preferência e os realmente adquiridos pelos consumidores de carne de frango do Alto Pantanal sul-mato-grossense.

A União Brasileira de Avicultura (UBABEF, 2012), ao realizar pesquisa com famílias de todas as regiões do Brasil, avaliando o consumo de carne de frango, obteve resultados semelhantes aos da presente pesquisa. A UBABEF observou que $20 \%$ das famílias preferem frango inteiro e que os cortes mais adquiridos são coxa e sobrecoxa (55\%), frango inteiro (53\%) e filé (46\%). Ainda de acordo com dados dessa instituição, cortes como tulipa (meio da asa), dorso e pescoço são os menos adquiridos, representando $2 \%, 5 \%$ e $6 \%$, respectivamente.

Para aquisição dos cortes de outras espécies animais (suína, caprina/ovina e pescado), a maior porcentagem dos entrevistados não soube opinar (84\%, 90\% e 78\%, respectivamente). Este fato pode estar relacionado à ausência de consumo dessas espécies ou à forma de aquisição pelo consumidor não ter sido considerada neste estudo.

Para os entrevistados que opinaram sobre o corte de peixe, a forma inteira foi a de maior consumo (10\%) e de maior aquisição (13\%). Para os cortes de carne suína (costela, lombo, paleta e pernil), também não foram observadas diferenças entre cortes preferidos e adquiridos, sendo a costela o de maior preferência (6\%) e aquisição (7\%). Para os cortes de caprinos/ovinos (costela, lombo e pernil), o pernil foi eleito o corte de maior preferência (5\%) e o mais adquirido para consumo (7\%).

Entre os consumidores de carne bovina, observase que $84 \%$ adquirem os cortes em açougues, solicitando o corte das peças no momento da compra. A aquisição dos cortes embalados a vácuo (1\%) ou previamente separados (5\%) foi citada por $1 \%$ e $5 \%$ dos entrevistados, respectivamente, não sendo usuais no município pesquisado. Esse comportamento em optar pela aquisição da carne "fresca", cortada no 
momento da compra, pode estar associado à melhor visualização da aparência da peça pelo consumidor, principalmente da cor da carne.

A aquisição da carne de frango pronta para o consumo em restaurantes e/ou churrascarias foi citada por apenas $1 \%$ dos entrevistados. Uma parcela significativa (28\%) dos entrevistados informou preferir adquiri-la a granel no expositor de carnes no comércio varejista, ao passo que 10\% informaram adquiri-la embalada em bandejas descartáveis e $4 \%$ embalada a vácuo. Contudo, a maior parte dos entrevistados (57\%) alegou que o modo de aquisição de carne de frango não se encaixava em nenhuma das opções descritas acima, demonstrando a diversidade de formas de comercialização dessa espécie animal.

Para as outras espécies animais estudadas (suína, caprina/ovina e pescado), a maior parte dos entrevistados não soube opinar sobre o modo de aquisição (84\%, 92\%, 80\%, respectivamente). Os que souberam opinar, informaram que adquirem essas carnes diretamente em açougues (14\% carne suína e $5 \%$ caprina/ovina) ou peixarias (9\%).

Para a carne bovina, $47 \%$ dos entrevistados escolheram a forma cozida em bifes como o modo de preparo mais usual. Para o preparo das carnes de frango (17\%), pescado (14\%) e suína (3\%), a forma mais comum de preparo foi por fritura, e para a carne de caprinos/ovinos, a forma assada (6\%).

Alguns fatores da vida moderna, como a falta de tempo e a maior participação feminina no mercado de trabalho, contribuíram para mudanças no modo de preparo da carne consumida. Dessa forma, a oferta de cortes com maior praticidade e rapidez de preparo são alternativas para o aumento e a constância do consumo desse alimento pelos consumidores.

\section{Conclusão}

Os consumidores do Alto Pantanal sul-matogrossense apresentam como preferência de consumo a carne bovina. A facilidade de crédito nos estabelecimentos de comércio de carne é um fator relevante para a fidelização dos consumidores nesses estabelecimentos. A praticidade, a disponibilidade, 0 custo e o sabor da carne são fatores que influenciam a escolha por uma determinada espécie animal. Os consumidores possuem conhecimento sobre a existência de selos de certificação de carne, porém não os exigem para a compra. 0 consumidor de carne bovina escolhe o corte em função do custo prioritariamente à preferência, comportamento não observado para as outras espécies animais.

\section{Agradecimentos}

Aos estabelecimentos comerciais do município de Aquidauana, MS, e à PROEC (Pró-Reitoria de Extensão, Cultura e Assuntos Comunitários) pelo apoio para a realização do projeto.

\section{Referências}

Almeida AR, Souza CC, Paim FC, Reis Neto JF. Identificar as características e as exigências do consumidor de carne de peixe na cidade de Campo Grande, MS. Congresso Internacional de Administração; 22-26 set 2014; Ponta Grossa, PR. Ponta Grossa: Universidade Estadual de Ponta Grossa; 2014

Bortoli EC, Barcelloes JOJ, Ceolin AC, Machado JD, Teixeira JL, Révillion JPP. Caracterização do consumidor de carne ovina na cidade de Porto Alegre. Rev CCEI. 2009; 13(24):28-35.

Brisola MV, Castro AMG. Preferências do consumidor de carne bovina do Distrito Federal pelo ponto de compra e pelo produto adquirido. Cad Pesqui Adm. 2005;12(1):81-99.

Dias LDB, Isernhagen L, Brumatti RC, Faria FJC, Franco GL, Kiefer C, et al. Estudo sobre o padrão de consumo da carne bovina na cidade de Campo Grande, MS, Brasil. B Industr Anim. 2015;72(2):148-54.

Diniz WJS, Almeida RB, Lima CN, Oliveira RR, Quirino WA, Brandespim DF. Perfil do consumidor e sua percepção sobre os aspectos higiênicos da comercialização de carnes em feiras livres. Acta Vet Brasilica. 2012;6(3):223-9.

Engel JF, Blackwell RD, Miniard PT. Comportamento do consumidor. Rio de Janeiro: LTC; 2000. 641 p. 
Francisco DC, Nascimento VP, Loguercio AP, Camargo L. Caracterização do consumidor de carne de frango da cidade de Porto Alegre. Cienc Rural. 2007;37(1):253-8.

Instituto Brasileiro de Geografia e Estatística - IBGE. Cidades: Mato Grosso do Sul: Aquidauana [acesso 29 ago 2016]. Disponível em: https://tinyurl.com/ybeyxklx.

Martins A, Aspinwall EM. Quality function deployment: an empirical study in the UK. Total Quality Management. 2001;12(5):575-88.

Raimundo LMB, Zen S. Aferição do perfil do consumidor de carne suína: estudo de caso Carrefour/Jundiaí (SP). 48ํㅜ Congresso Sociedade Brasileira de Economia Administração e Sociologia Rural; 25-28 jul 2009; Campo Grande, MS. Brasília: SOBER, 2010.

Raimundo LMB, Batalha MO. Mercado de carne suína na cidade de São Paulo: segmentos e estratégias. Gest Prod. 2015;22(2):391-403.
Santos TMB, Cappi N, Simões ARP, Santos VAC, Paiano D, Garcia ERM. Diagnóstico do perfil do consumidor de carne suína no município de Aquidauana-MS. Rev Bras Saude Prod An. 2011;12(1):1-13.

Sório AM, Mariani M. A carne ovina como possibilidade de desenvolvimento do turismo com base regional e local. V Seminário de Pesquisa em Turismo do MERCOSUL (SeminTUR); 27-28 jun 2008; Caxias do Sul, RS. Caxias do Sul: Universidade de Caxias do Sul; 2008.

União Brasileira de Avicultura (UBABEF). Carne de frango, unanimidade que vai do Norte ao Sul do Brasil. Rev Avicultura Brasil. 2012;1:8-14. Disponível em: https://tinyurl.com/y8n9sxdz. 